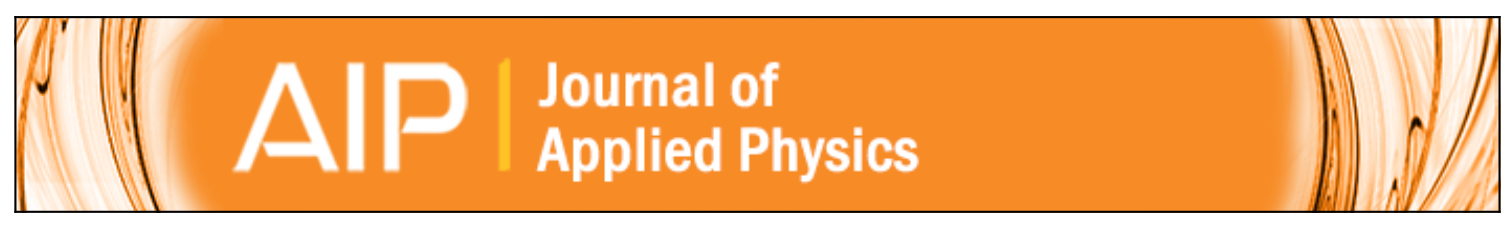

\title{
Phase separation in ion bombarded FeNi Invar alloys
}

M. R. Gallas, L. Amaral, and J. A. H. da Jornada

Citation: Journal of Applied Physics 70, 131 (1991); doi: 10.1063/1.350325

View online: http://dx.doi.org/10.1063/1.350325

View Table of Contents: http://scitation.aip.org/content/aip/journal/jap/70/1 ?ver=pdfcov

Published by the AIP Publishing

\section{$\stackrel{A}{A} P(P)$ Re-register for Table of Content Alerts}

Create a profile. 


\title{
Phase separation in ion bombarded FeNi Invar alloys
}

\author{
M. R. Gallas, L. Amaral, and J. A. H. da Jornada \\ Instituto de Fisica, Universidade Federal do Rio Grande do Sul, 91500 Porto Alegre, Brazil
}

(Received 14 November 1990; accepted for publication 1 April 1991)

\begin{abstract}
Studies of the effects of ion bombardment on the phase equilibria and ordering of FeNi alloys with 30.6 and 39.5 at. \% Ni were performed. The FeNi samples were bombarded with $\mathrm{Ne}, \mathrm{Ar}$, and $\mathrm{Kr}$ at different doses and temperatures, and analyzed using the conversion electron Mössbauer spectroscopy (CEMS) technique with ${ }^{57} \mathrm{Fe}$. The changes in the CEMS spectra of $\mathrm{Fe}_{69.4} \mathrm{Ni}_{30.6}$ and $\mathrm{Fe}_{60.5} \mathrm{Ni}_{39.5}$ alloys, bombarded with $\mathrm{Ne}$ and $\mathrm{Ar}$, indicate a phase separation, but no evidence of ordering. The $\mathrm{Kr}$ bombardment does not produce any change, however samples of 39.5 at. \% Ni already showing phase separation returned to the single phase state after $\mathrm{Kr}$ irradiation. Our results give strong evidences of a prevalence of displacement mixing for bombardment with heavier ions, and of radiation enhanced diffusion for bombardment with lighter ions.
\end{abstract}

\section{INTRODUCTION}

Iron-nickel alloys in the composition range from 30 to 50 at. \% Ni have been extensivcly studied, mostly because of the Invar phenomena. ${ }^{1}$ It is known that for these alloys, important structural changes like atomic ordering and clustering should take place below $700 \mathrm{~K}^{2-4}$ At such low temperature, diffusion is extremely sluggish, so a real equilibrium is hardly achieved. In FeNi alloys found in meteorites, a state closer to the thermodynamical equilibrium can be observed because the cooling rates are very slow, about $1 \mathrm{~K}$ per $10^{6}$ years. In order to attain a state closer to equilibrium at reasonable experimental times, it is necessary to use special techniques for increasing diffusion, like electron and neutron irradiation ${ }^{5-7}$ or ultrafine particles. ${ }^{8,9}$ These works show a tendency to produce phase separation and ordering, very similar to the ones found in FeNi meteorites..$^{10,11}$

Ion irradiation is a very interesting technique to be used in connection with this problem. Besides more complicated phenomena, it can produce two important effects: for one side, it can enhance the diffusion by the so-called radiation enhanced diffusion effect, which in principle could generate the same stable phases produced by the techniques referred above. On the other side, it will also produce displacement mixing, which tends to homogenize the system, producing a more random distribution of $\mathrm{Ni}$ and $\mathrm{Fe}$ atoms. Indeed the two aspects are interesting, because these alloys are not only difficult to be produced in an ordered way, but also a completely random distribution of the atoms seems to be very difficult to be achieved. ${ }^{12,13}$ The importance of having tools either for producing a truly randomly mixed alloy or producing a state closer to the true thermodynamical equilibrium (which for this system means atomic ordering and phase separation), lies not only in the metallurgical aspects. In fact, Invar properties are known to be strongly dependent on atomic ordering. ${ }^{14,15}$ Preliminary results, using Ar ions, ${ }^{16}$ showed a phase separation in $\mathrm{Fe}_{60} \mathrm{Ni}_{40}$ alloys.

In this work we study the atomic rearrangements produced by ion bombardment in Invar FeNi alloys, with composition of 39.5 and 30.6 at. \% Ni, through conversion electron Mössbauer spectroscopy (CEMS). Different noble gases ions have been bombarded with variable doses and energy, al different substrate temperatures.

\section{EXPERIMENT}

FeNi samples with composition of 30.6 and 39.5 at. \% $\mathrm{Ni}$ and a purity better than 99.9 at. \% for $\mathrm{Fe}$ and $\mathrm{Ni}$, were laminated and then annealed for $1 \mathrm{~h}$ in vacuum better than $10^{-4} \mathrm{~Pa}$ at a temperature of $1273 \mathrm{~K}$.

The samples were analyzed through the conversion electron Mössbauer spectroscopy (CEMS) technique using a ${ }^{57} \mathrm{Co} R h$ source. The measurements have been done in a conventional Mössbauer setup operating in the constant acceleration mode.

The ion irradiation with $\mathrm{Ne}, \mathrm{Ar}$, and $\mathrm{Kr}$ were done at the HVEE 400-kV ion implanter of the Institut of Physics, Porto Alegre. The implantation current density was controlled in order to avoid undesirable heating of the samples. The implantation energies were set to produce a bombarded region of around $2000 \AA$, that is about the CEMS penetration depth.

As noble gas ions are not expected to produce chemical effects, in order to see the influence of ion mass we compare the results for different conditions, but with approximately the same displacement per atom (dpa) and mean projected range, that were evaluated through the TRIM code. ${ }^{17} \mathrm{We}$ selected a dpa around 85 , based on our preliminary work, ${ }^{16}$ which shows a clear phase separation for Ar bombardment in $\mathrm{Fe}_{60} \mathrm{Ni}_{40}$ at this conditions. The different ion irradiation parameters are summarized in Tables I and II for $\mathrm{Fe}_{60.5} \mathrm{Ni}_{39.5}$ and $\mathrm{Fe}_{69.4} \mathrm{Ni}_{30.6}$ samples, respectively, as well as the hyperfine parameters obtained.

\section{RESULTS AND DISCUSSION}

Typical CEMS spectra are shown in Figures 1-4, for different cases in the $\mathrm{Fe}_{60.5} \mathrm{Ni}_{39.5}$ and $\mathrm{Fe}_{69.4} \mathrm{Ni}_{30.6}$ samples. Tables I and II show the hyperfine parameters for these samples. 
TABLE I. Irradiation conditions and hyperfine parameters for the $\mathrm{Fe}_{60.5} \mathrm{Ni}_{39.5}$ sample. $I=$ ion; $E=$ energy; $D=$ dose; $S T=$ substrate temperature, dpa $=$ displacement per atom; $H=$ hyperfine field; $I S=$ isomer shift; $\Gamma=$ linewidth; $A=$ relative area. In all the cases, the beam current intensity was lower than $1 \mu \mathrm{A} / \mathrm{cm}^{2}$, in order to avoid excessive heating of the sample.

\begin{tabular}{|c|c|c|c|c|c|c|c|c|}
\hline \multirow[b]{2}{*}{$I$} & \multicolumn{3}{|c|}{ Irradiation conditions } & & \multicolumn{4}{|c|}{ Hyperfine parameters } \\
\hline & $\begin{array}{c}E \\
\mathrm{keV}\end{array}$ & $\begin{array}{c}D \\
\text { ions } \mathrm{cm}^{-2}\end{array}$ & $\begin{array}{l}S T \\
\mathbf{K}\end{array}$ & dpa & $\begin{array}{c}H \\
\mathrm{kG} \\
\pm 2\end{array}$ & $\begin{array}{c}I S \\
\mathrm{~mm} \mathrm{~s}^{-1} \\
\pm 0.01\end{array}$ & $\begin{array}{c}\Gamma \\
\mathrm{mm} \mathrm{s}^{-1} \\
\pm 0.02\end{array}$ & $\begin{array}{l}A \\
\% \\
\pm 2\end{array}$ \\
\hline \multirow[b]{3}{*}{$\mathrm{Ne}$} & & unirradiated & & & 295 & -0.100 & 0.64 & 60 \\
\hline & & [Fig. $1(a)]$ & & & 310 & -0.068 & 0.38 & 40 \\
\hline & 210 & $8.4 \times 10^{16}$ & 300 & 85 & 300 & -0.062 & 0.70 & 61 \\
\hline \multirow{2}{*}{ Ar } & & [Fig. (2)] & & & 320 & -0.072 & 0.44 & 52 \\
\hline & & & & & $\cdots$ & -0.185 & 0.35 & 8 \\
\hline \multirow[t]{2}{*}{$\mathbf{K r}$} & 760 & $10^{16}$ & 300 & 107 & 295 & -0.079 & 0.71 & 83 \\
\hline & & [Fig. 1(c)] & & & 310 & -0.084 & 0.39 & 17 \\
\hline
\end{tabular}

For the unirradiated sample the CEMS spectrum [Fig. 1 (a)] shows two very close magnetic sextets, which is in good agreement with previous results. ${ }^{2,10,18}$ The spectra obtained after bombardment with Ne show a single central peak, in addition to the magnetic sextets [Fig. 1(b)]. This new singlet is well known for spectra of meteorites and in FeNi samples irradiated with electrons and neutrons, 2,10 identifying the onset of a paramagnetic phase. According to previous studies, ${ }^{2,10}$ this phase has a low concentration of $\mathrm{Ni}$, but has the same fcc structure as the ferromagnetic coexisting phase, and remains metastable due to the small size of their clusters.

Using $\mathrm{Ar}$ ions, instead of $\mathrm{Ne}$, for the 39.5 at. \% Ni sample, we obtained similar results, but for the same dpa and substrate temperature during bombardment ( $300 \mathrm{~K})$, we observed a lower intensity of the central peak (Fig. 2).

Doing the same experiment with the $\mathbf{K r}$ ion, we observed no central peak formation, and the spectra remain basically the same, even for very high dpa. We propose that this kind of result could be explained by a competition between two effects: radiation enhanced diffusion (which in this specific case would lead to phase separation and eventually ordering in one of these phases) and displace- ment mixing (which tends to homogenize the system) so, it seems that if we maintain the same dpa, the relative importance of the radiation enhanced diffusion mechanism is stronger for lighter ions ( $\mathrm{Ne}$ ), decreasing for $\mathrm{Ar}$ ions, and is totally suppressed by the displacement mixing effect in the case of the heavier $\mathbf{K r}$ ion. This increased importance of the displacement mixing for heavier ions is in agreement with previous results observed on $\alpha$-iron irradiated with heavy ions by Jenkins, English, and Eyre. ${ }^{19}$ It was observed that the cascade becomes denser and more localized, when it was increased the incident ion mass, which enhance the local vacancy concentration tending to an aggregation and loop formation. This kind of process could increase displacement mixing and prevent the vacancies from moving through the lattice helping diffusion.

In order to test this hypothesis, we bombarded with $\mathrm{Kr}$ a sample previously bombarded with $\mathrm{Ne}$, that showed a strong central peak, as displayed in Fig. 1(b). As a consequence of $\mathrm{Kr}$ bombardment the central peak produced by the previous Ne irradiation disappeared totally, suggesting again a predominant displacement mixing effect [Fig. $1(\mathrm{c})]$.

It is well known that ordered samples found in neutron

TABLE II. Irradiation conditions and hyperfine parameters for the $\mathrm{Fe}_{69.5} \mathrm{Ni}_{30.6}$ sample. $I=$ ion; $E=$ energy; $D=$ dose; $S T=$ substrate temperature, dpa $=$ displacement per atom; $H=$ hyperfine field; $I S=$ isomer shift; $\Gamma=$ linewidth; $A=$ relative area.

\begin{tabular}{|c|c|c|c|c|c|c|c|c|}
\hline \multirow[b]{2}{*}{$I$} & \multicolumn{3}{|c|}{ Irradiation conditions } & \multirow[b]{2}{*}{ dpa } & \multicolumn{4}{|c|}{ Hyperfine parameters } \\
\hline & $\underset{\mathrm{keV}}{E}$ & $\begin{array}{c}D \\
\text { ions } \mathrm{cm}^{-2}\end{array}$ & $\begin{array}{c}S T \\
\mathbf{K}\end{array}$ & & $\begin{array}{c}H \\
k G \\
\pm 2\end{array}$ & $\begin{array}{c}I S \\
\mathrm{~mm} \mathrm{~s}^{-1} \\
\pm 0.01\end{array}$ & $\begin{array}{c}\mathrm{mm} \mathrm{s}^{-1} \\
\pm 0.02\end{array}$ & $\begin{array}{l}A \\
\% \\
\pm 2\end{array}$ \\
\hline & & unirradiated & & & $\cdots$ & -0.120 & 1.64 & 47 \\
\hline & & [Fig. 3(a)] & & & 118 & -0.091 & 1.39 & 53 \\
\hline $\mathrm{Ne}$ & 210 & $8.4 \times 10^{16}$ & 300 & 85 & $\ldots$ & -0.190 & 0.37 & 57 \\
\hline \multirow{2}{*}{$\mathrm{Ne}$} & & (Fig. 4) & & & 200 & 0.011 & 0.70 & 24 \\
\hline & & & & & 275 & -0.033 & 0.70 & 26 \\
\hline \multirow[t]{3}{*}{$\mathrm{Kr}$} & $\therefore 760$ & $10^{16}$ & 300 & 107 & $\ldots$ & -0.170 & 0.86 & 57 \\
\hline & & (Fig. 3c) & & & 200 & 0.011 & 0.70 & 10 \\
\hline & & & & & 275 & -0.033 & 0.70 & 33 \\
\hline
\end{tabular}




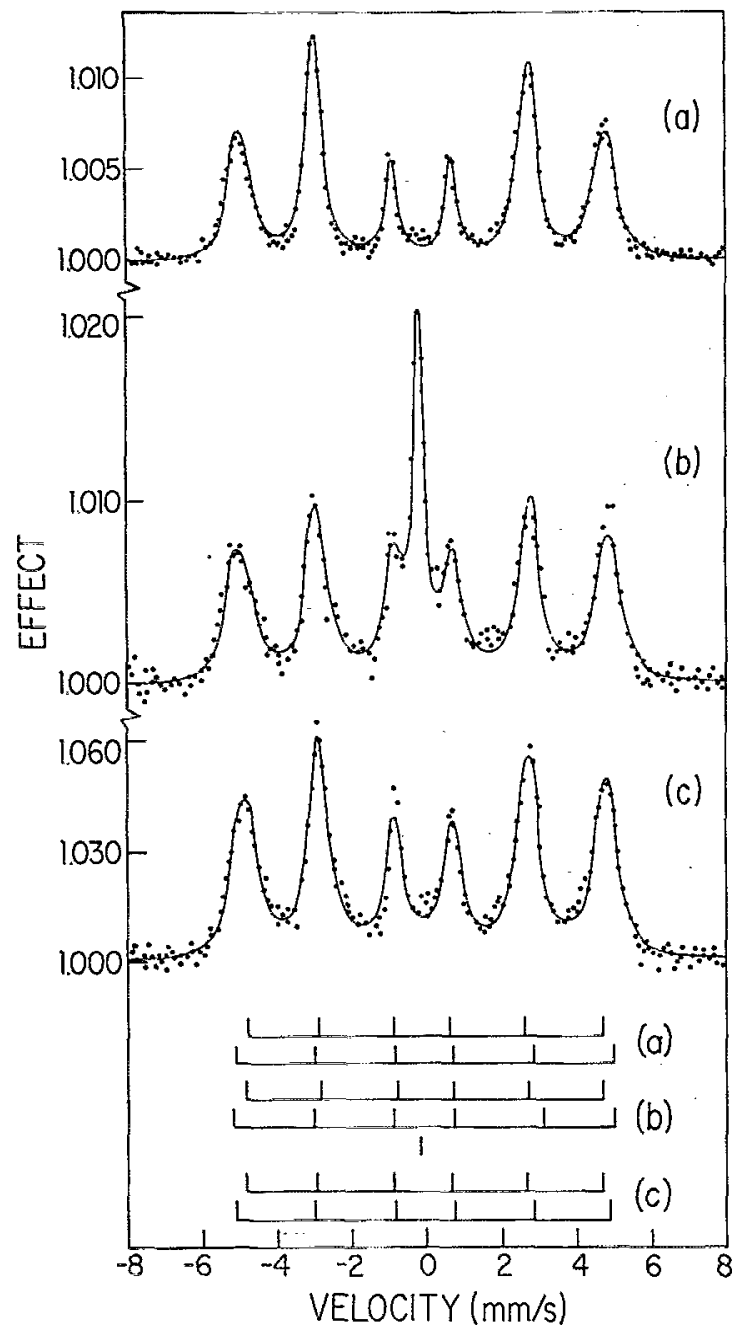

FIG. 1. Mössbauer spectra for $\mathrm{Fe}_{60.5} \mathrm{Ni}_{39.5}$ sample: (a) unirradiated; (b) bombarded with $\mathrm{Ne}$ at room temperature (dose $=8.4 \times 10^{16}$ ions $\mathrm{cm}^{-2}$, energy $=210 \mathrm{keV}$, dpa $=85$ ); (c) sample bombarded as in (b), with further bombardment with $\mathrm{Kr}$ at room temperature (dose $=10^{16}$ ions $\mathrm{cm}^{-2}$, energy $=760 \mathrm{keV}, \mathrm{dpa}=107$ ).

or electron irradiated alloys or meteorites shows a quadrupole splitting due to a noncubic $\mathrm{L} 1_{0}$ structure, ${ }^{2,10}$ but in our spectra no strong evidence of ordering of a possible $\mathrm{Ni}$ enriched phase is present.

We performed a similar study also for samples with composition more to the end of the Invar region, namely 30.6 at. \% Ni. For the unirradiated case [Fig. 3(a)], the CEMS spectrum shows a broad distribution of magnetic field that can be fitted with a broad central peak and a small magnetic sextet (see Table II). For the Ne bombardment [Fig. 3(b)], the central peak becomes sharp, and the broad part of the spectrum disappears yielding a lower contribution of a more defined magnetic sextet, with smaller relative area, that represents a composition rich in $\mathrm{Ni}$, according to the known dependence of the magnetic hyperfine fields with concentration. ${ }^{20}$ When this same $\mathrm{Ne}$ bombarded samples was later irradiated with $\mathrm{Kr}$ [Fig. 3(c)], it was not observed a complete reversion to the unir- . radiated situation, as for the previous case. However, a

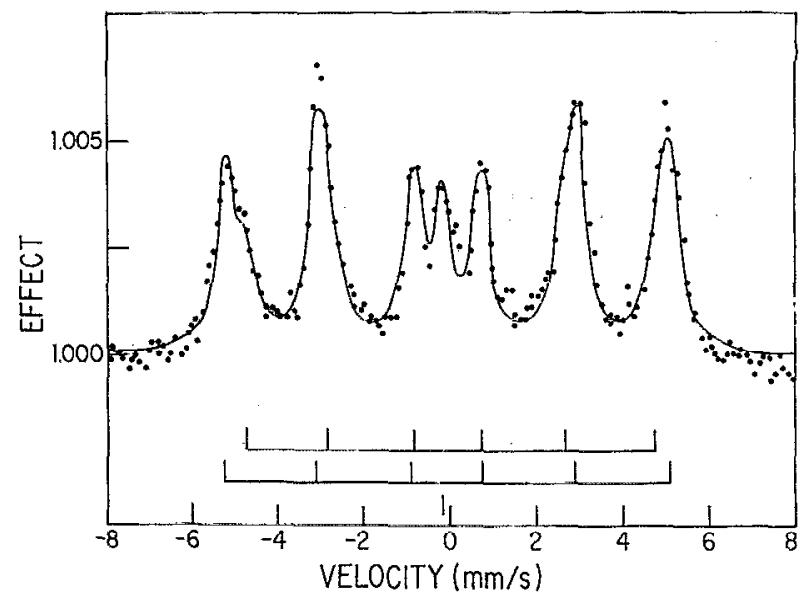

FIG. 2. Mössbauer spectrum for $\mathrm{Fe}_{60.5} \mathrm{Ni}_{39.5}$ sample bombarded with $\mathrm{Ar}$ at room temperature (dose $=4 \times 10^{16}$ ions $\mathrm{cm}^{-2}$, energy $=370 \mathrm{keV}$, $\mathrm{dpa}=85$ ).

clear tendency to revert the effect was observed, namely, the central peak broadens and the value of the magnetic field decreases, indicating a predominance of displacement mixing, in a way similar to that for the 39.5 at. \% Ni alloy.

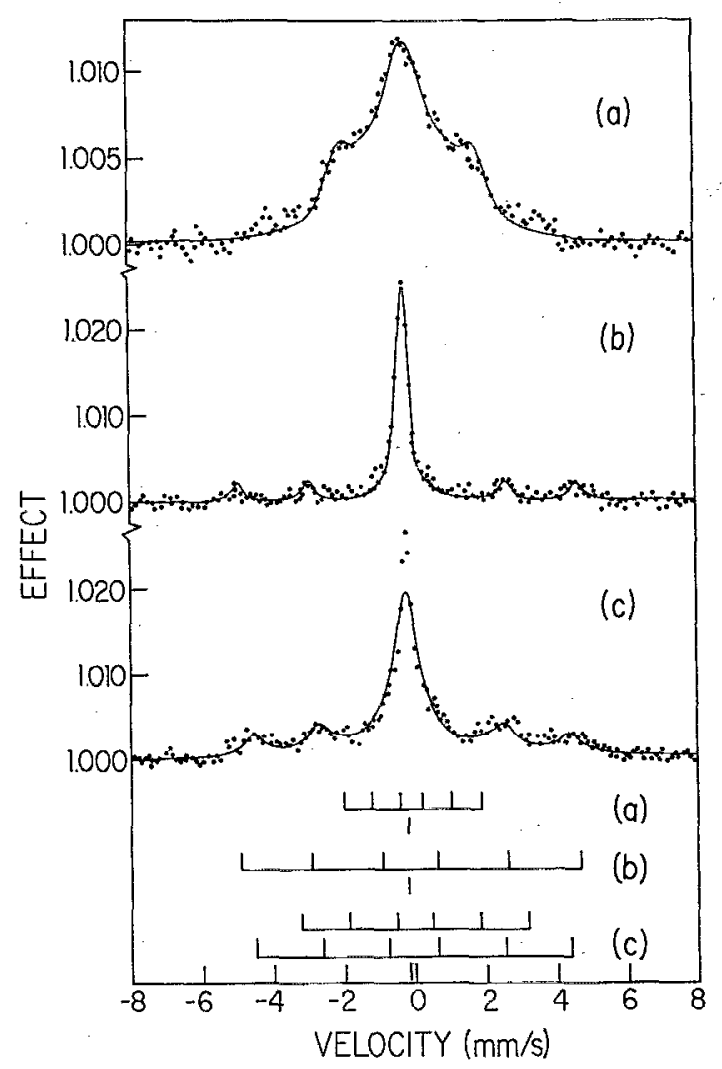

FIG. 3. Mössbauer spectra for $\mathrm{Fe}_{69.4} \mathrm{Ni}_{30.6}$ sample: (a) unirradiated; (b) bombarded with $\mathrm{Ne}$ at room temperature (dose $=8.4 \times 10^{16}$ ions $\mathrm{cm}^{-2}$, energy $=210 \mathrm{keV}$, dpa $=85$ ); (c) sample bombarded as in (b), with further bombardment with $\mathrm{Kr}$ at room temperature (dose $=10^{16}$ ions $\mathrm{cm}^{-2}$, energy $=760 \mathrm{keV}, \mathrm{dpa}=107$ ). 


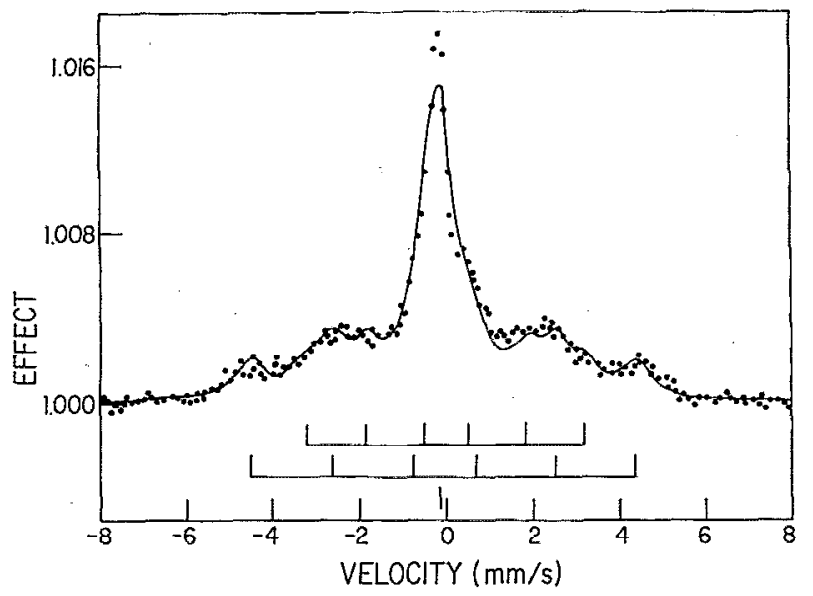

FIG. 4. Mössbauer spectrum for $\mathrm{Fe}_{69.4} \mathrm{Ni}_{30.6}$ sample bombarded with $\mathrm{Ne}$ at $473 \mathrm{~K}$ (dose $=8.4 \times 10^{16}$ ions $\mathrm{cm}^{-2}$, energy $=210 \mathrm{keV}$, dpa $=85$ ).

In Fig. 4 we present the spectrum for the sample of 30.6 at. \% Ni also bombarded with $\mathrm{Ne}$, but at $473 \mathrm{~K}$, in order to see the effect of the sample temperature. As this spectrum is similar to the previous case [Fig. 3(c)], we started with the same fitting parameters, and noted that the relevant change was only in the relative area, showing that only the proportion of the phases was changed. As can be seen, the irradiation effect is different compared to the room-temperature bombarded samples and shows a less pronounced sharpness of the central peak. This fact is in agreement with the decreasing of the thermodynamical driving force for phase separation with increasing temperature. Studies of the FeNi phase diagram in the rather low-temperature range suggest a temperature about $723 \mathrm{~K}$ as the dome for the miscibility gap in this region of $30-40$ at. \% Ni. ${ }^{21}$ This is also in qualitative agreement with our experiments involving the effect of annealing on the spectra of bombarded samples, where we found that the spectra for the 40 at. \% Ni practically returned to the original unirradiated form, for annealing temperature of $773 \mathrm{~K}$ during $1 \mathrm{~h}$.

\section{CONCLUSIONS}

In this work we made an investigation of the effect of ion bombardment, with different noble gas ions, on the phase structure of FeNi Invar alloys, at compositions of 30.6 and 39.5 at. \% Ni. We observed a clear phase separation for $\mathrm{Ne}$, the same effect but not so strong for $\mathrm{Ar}$, and a reverse effect for $\mathrm{Kr}$. These results are interpreted as evidence that for lighter ions the radiation enhanced diffusion effect is predominant, whereas for the heavier ions we studied $(\mathrm{Kr})$, the displacement mixing effect is dominant.
It is interesting to note that a similar effect was observed by Jenkins et al. ${ }^{19}$ in a study of $\alpha$-iron irradiated with heavy ions.

The temperature at which the phase separation disappears, as well as the kind of spectra, is very similar to the already studied case of neutron and electron irradiation, 2,10 however we did not find enough evidence of ordering. Probably the mixing effect associated with ion bombardment is sufficient, even for $\mathrm{Ne}$, to mix the atoms in the very short range necessary for ordering, but this mixing is not enough to mix larger regions of the clusters formed by the phase separation.

It is important to point out, finally, the advantage of ion bombardment as a powerful tool for producing Invar alloys not only in the more stable state of two phases, as in neutron and electron irradiation, but also in the more random state, through the use of heavy ions, which is very interesting due to the dependence of the Invar properties with atomic order.

\section{ACKNOWLEDGMENTS}

The authors thank Professor J. Danon (deceased) for helpful discussions. We also wish to thank Professor $\mathbf{M}$. Behar for clarifying discussions. This work was supported in part by CAPES, CNPq, and FINEP.

${ }^{1}$ E. F. Wassermann, in Festkörperproblem (Advances in Solid State Physics), edited by P. Grosse (Vieweg, Braunschweig, 1987), Vol. 27, p. 85.

${ }^{2}$ H. Rechenberg, $\mathrm{Ph} . \mathrm{D}$. thesis, Universite de Grenoble, 1973.

${ }^{3}$ D. G. Rancourt, H. H. A. Smit, and R. C. Thiel, J. Magn. Magn. Mater. 66, 121 (1987).

${ }^{4}$ M. R. Gallas and J. A. H. da Jornada, J. Phys. Cond. Mat. 3, 155 (1991).

${ }^{5}$ H. Morita, A. Chamberod, and S. Steinemann, J. Phys. F 14, 3053 (1984).

${ }^{6} \mathrm{H}$. Morita, Y. Tanji, H. Hiroyoshi, and Y. Nakagawa, J. Magn. Magn. Mater. 31-34, 107 (1983).

${ }^{7}$ K. C. Russell and F. A. Garner, Metall. Trans. A 21A, 1073 (1990).

${ }^{8} \mathrm{H}$. Franco and H. Rechenberg, J. Phys. F (GB) 15, 719 (1985).

${ }^{9}$ C. Kaito, Y. Saito, and K. Fujita, Jpn. J. Appl. Phys. 28, L694 (1989).

${ }^{10}$ R. B. Scorzelli and J. Danon, Phys. Scripta 32, 143 (1985).

${ }^{11}$ R. A. Jago, P. E. Clark, and P. I. Rossiter, Phys. Status Solidi A 74, 247 (1982).

${ }^{12}$ G. Dumpich, E. Becker, K. Schletz, W. Stamm, W. Keune, W. Kiauka, and S. Murayama, J. Magn. Magn. Mater. 74, 237 (1988).

${ }^{13}$ H. Morita, H. Hiroyoshi, H. Fujimore, and Y. Nakagawa, J. Magn. Magn. Mater. 15-18, 1197 (1980).

${ }^{14}$ Y. Nakamura, M. Shiga, and N. Shikazono, J. Phys. Soc. Jpn. 19, 1177 (1964).

${ }^{15}$ Y. Kakehashi, Phys. Rev. B 38, 474 (1988).

${ }^{16}$ M. R. Gallas, L. Amaral, and J. A. H. da Jornada, Proc. of Latin American Conference on the Applications of Mössbauer Effect (LACAME 88), Rio de Janeiro (World Scientific, Singapore, 1988), p. 239.

${ }^{17}$ J. F. Ziegler, J. P. Biersack, and U. Littmark, The Stopping and Range Ions into Solids, edited by J. F. Ziegler (Pergamon, New York, 1985).

${ }^{18}$ L. Billard and A. Chamberod, Solid State Commun. 17, 113 (1975).

${ }^{19}$ M. L. Jenkins, C. A. English, and B. L. Eyre, Philos. Mag. A 38, 97 (1978).

${ }^{20}$ C. E. Johnson, M. S. Ridout, and T. E. Cranshaw, Proc. Phys. Soc. 81, 1079 (1963).

${ }^{21}$ K. B. Reuter, D. B. Williams, and J. I. Goldstein, Metall. Trans. A 20A, 719 (1989). 